\title{
Endodontic management of a maxillary second molar with five root canals: a case report
}

\author{
Gülşah Uslu, ${ }^{1}$ Taha Özyürek, ${ }^{2}$ Koray Yılmaz $^{3}$ \\ 'Private Practice, Çanakkale, Turkey \\ ${ }^{2}$ Department of Endodontics, Ondokuz Mayıs University Faculty of Dentistry, Samsun, Turkey \\ ${ }^{3}$ Oral and Health Center, Çorum, Turkey
}

\begin{abstract}
A maxillary second molar tooth with two palatal roots is an uncommon anomaly. In this case report, we describe non-surgical endodontic treatment of a maxillary second molar with two palatal roots. The second palatal root was discovered during preparation of the endodontic access cavity. Biomechanical preparation of all root canals was performed using nickel-titanium (NiTi) rotary instruments. Root canal obturation was performed with a root canal sealer and gutta-percha cones using the lateral compaction technique. The tooth was then restored with composite resin. It may be difficult to detect extra roots in the maxillary posterior region on radiographs because of superposition of various anatomic structures. A careful examination of the pulp chamber can aid in detecting extra canals that are not radiographically visible.
\end{abstract}

Keywords: Anatomic variations; endodontics; root canal anatomy; second palatal root; upper second molar.

$\mathrm{T}_{\mathrm{i}}$ he success of endodontic treatment depends on filling the root canal system after careful cleaning. To minimize the risk of failure arising from insufficient cleaning and filling of the root canal, a complete picture of the anatomy of the root canal system of the tooth to be treated is needed. ${ }^{[1]}$

In terms of anatomy, maxillary second molars are generally similar to maxillary first molars. A distinguishing characteristic of maxillary second molars is convergence of three roots, with complete unification of these roots in some cases. In addition, maxillary second molars have shorter and curved roots than maxillary first molars. Maxillary second molars generally have just a single canal in each root. ${ }^{[2]}$ Compared with maxillary first molars, they are less likely to have a secondary canal in the mesiobuccal root. According to previous studies, the incidence of a second mesiobuccal canal in maxillary second molars is $24.3 \%,{ }^{[3]}$ whereas that of maxillary second molars with four roots is $0.4 \% \cdot{ }^{[4]}$ Another study reported an incidence of the aforementioned variation of approximately $1.4 \%$. ${ }^{[5]}$ Although it is easy to clinically detect these two palatal canals that have significantly low incidences, they may be undetected during root canal treatment because of superposition that occurs on radiography. Thus, it is important to check for the presence of extra palatal roots and canals during root canal treatment of maxillary second molars. In this case report, we describe endodontic treatment of a maxillary second molar with five canals, two of which were palatal.

Correspondence: Dr. Gülşah Uslu. Şirintepe Mahallesi Derya Sok., No: 18,

Biga, 17200 Çanakkale, Turkey.

Tel: +90 553 - 3620681 e-mail: gulsah.turkkan@hotmail.com

Submitted: November 13, 2017 Accepted: March 13, 2018 


\section{Case report}

A 31-year-old female presented to our clinic with a complaint of constant pain in the left maxillary region. A detailed medical history revealed no systemic disease. On radiological and clinical examinations, a deep caries cavity was observed mesial to the second maxillary molar. On radiographic imaging, the periapical tissues appeared healthy (Fig. 1). On an electrical vitality test, the relevant tooth positively responded compared with a control tooth. Based on results of clinical tests and radiographic evaluations, the patient was diagnosed with symptomatic irreversible pulpitis.

Local anesthesia of the second maxillary molar was induced via the infiltration method using $2 \mathrm{ml}$ of articaine solution containing 1/100000 epinephrine (Ultracain DS Forte; Aventis, Turkey). After ensuring sufficient depth of the local anesthetic, the relevant tooth was isolated using a rubber dam. Following cleaning of the carious lesion, an endodontic access cavity was prepared. An examination of the pulpal chamber showed that the palatal canal orifice was located too distal and that the palatal segment of the pulpal chamber was enlarged toward the mesial, indicating the potential presence of a secondary palatal canal. After fixing the palatal canal orifice, the shape of the access cavity was modified to a rectangular form rather than the conventional triangular form to ensure smoother access to all the canals (Fig. 2). A secondary mesiobuccal canal was found in the palatal of the mesiobuccal canal. In total, five canals were detected.

A glide path was prepared using a \#10 K-type file, and canal lengths were determined using an electronic apex finder (Root ZX mini; J. Morita Corp., Kyoto, Japan). Root canals were prepared using Mtwo (VDW, Munich, Germany) NiTi rotary files (up to $30 / .05$ in buccal root canals and 40/.04 in palatal root canals). The canals were

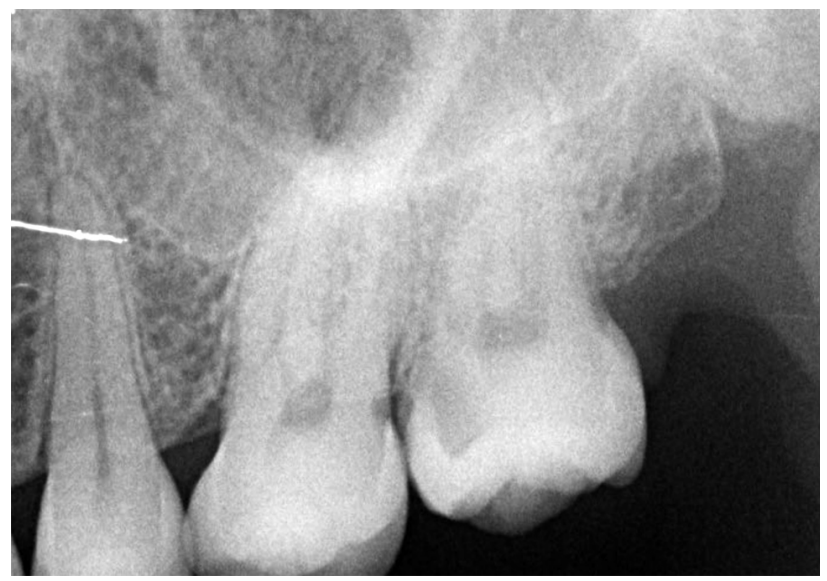

Fig. 1. Preoperative radiographic image of the maxillary second molar tooth. irrigated after each change of file, with $1 \mathrm{ml}$ of $5.25 \%$ sodium hypochlorite $(\mathrm{NaOCl})$ solution applied to each canal. Before commencing root canal filling procedures, gutta-percha cones compatible with the final rotary files were placed in the canals. Radiographic imaging was then performed for checking dimensions of the shape (Fig. 3).

After confirming locations of gutta-percha cones on the apex, each canal was irrigated using $2 \mathrm{ml}$ of $17 \%$ EDTA (Werax, Izmir, Turkey) for $2 \mathrm{~min}$ and $2 \mathrm{ml}$ of $5.25 \% \mathrm{NaOCl}$ solution to remove the smear layer. After drying the canals with sterile paper cones, 2Seal (VDW, Munich, Germany) canal filling paste and gutta-percha

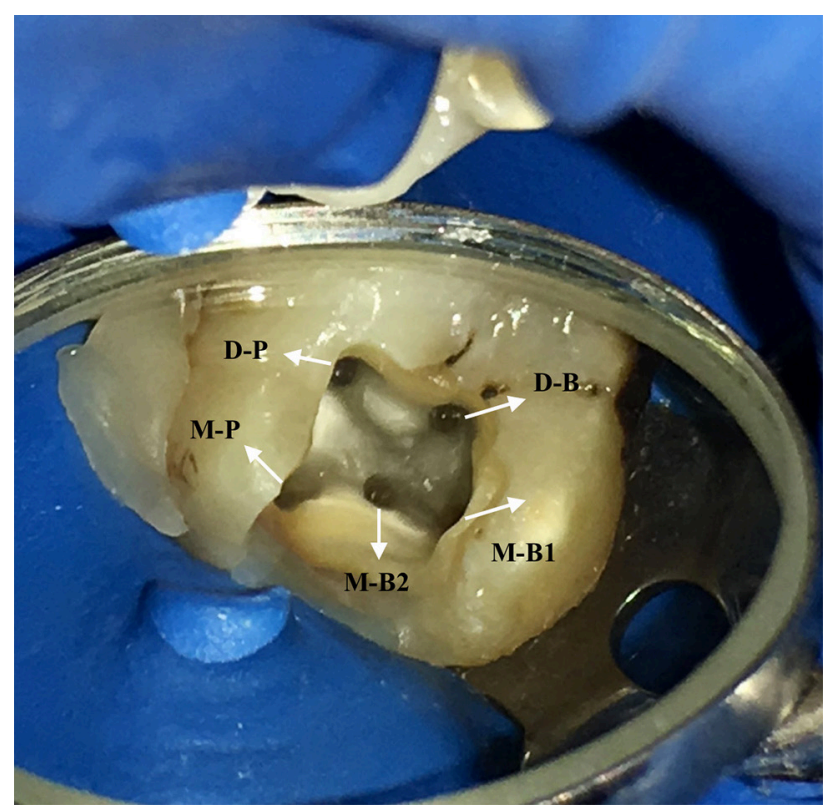

Fig. 2. Intra-oral image of five canal orifices of the maxillary second molar tooth (M-B: mesiobuccal; D-B: distobuccal; M-P: mesiopalatal; and D-P: distopalatal).

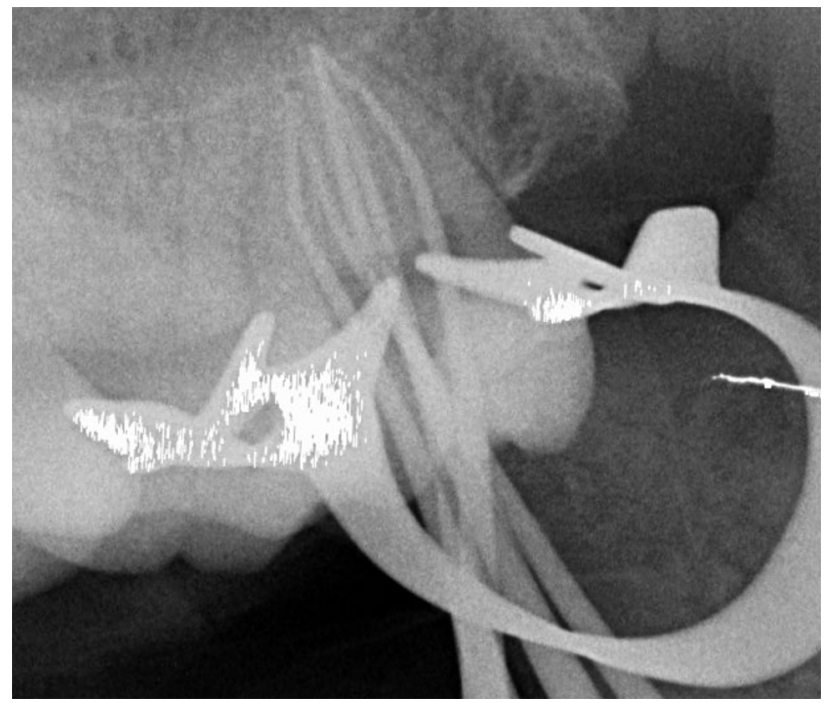

Fig. 3. Radiograph with five master cones. 


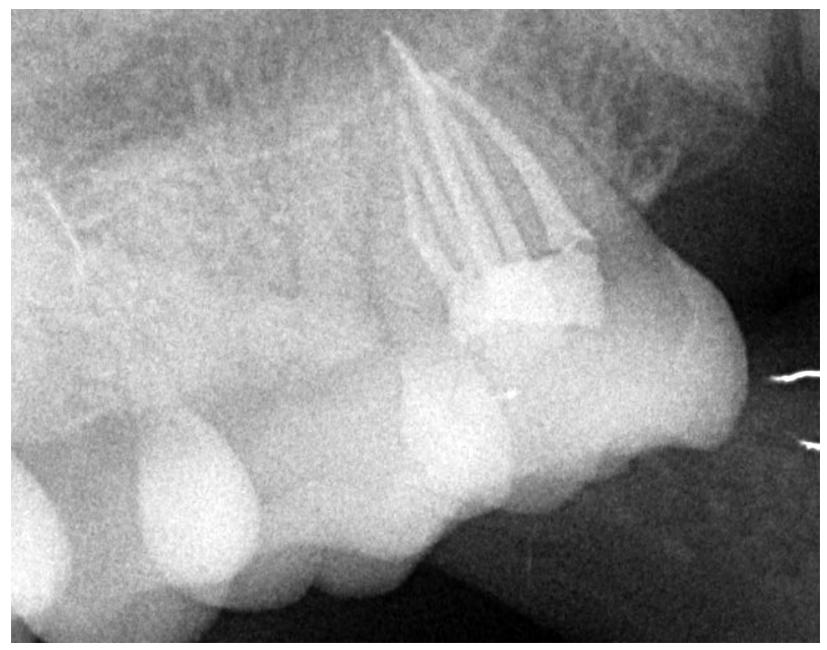

Fig. 4. Postoperative radiograph of the maxillary second molar tooth.

cones (VDW) were used for filling the root canals using the lateral compaction method. Restoration of the relevant tooth was performed using X-tra base (Voco GmbH, Cuxhaven, Germany) bulk-fill and Gradia Posterior (GC) composite resins (Fig. 4).

\section{Discussion}

A secondary mesiobuccal canal is the most common extra canal observed in maxillary molars. Pécora et al. ${ }^{[6]}$ reported an incidence of $42 \%$ secondary mesiobuccal canals in decalcified maxillary second molars. Lee et al. ${ }^{[7]}$ confirmed this finding in a cone-beam computed tomography $(\mathrm{CBCT})$ study. However, it is difficult to detect secondary mesiobuccal canals during routine root canal treatment. ${ }^{[3]}$

The presence of a secondary palatal canal (i.e., an extra canal) in maxillary molars is very rare, particularly in maxillary second molars. ${ }^{\left[{ }^{[1]}\right.}$ Retrospective studies failed to detect any maxillary second molars with two palatal roots. ${ }^{[9-11]}$ Christie et al ${ }^{[12]}$ reported that the incidence of maxillary molars with two palatal roots or canals in clinical practice was very low, with such variation observed only once every 3 years. The aim of the present case report was to add to the literature by describing endodontic treatment of a maxillary second molar with five canals, two of which were palatal canals.

It is difficult to detect unusual canal anatomies in maxillary teeth because of their posterior location. On radiography, the detection of a second palatal canal is hampered by superposition of anatomic structures in the region. ${ }^{[13]}$ Knowledge of anatomical variations and abnormalities frequently observed in this region together with radiographs taken from different angles and a CBCT study can aid detection. ${ }^{[14]}$ In cases where radiography fails to determine the presence of extra canals, a careful analysis of developmental grooves in the pulpal chamber base by the dentist can aid detection of such canals. ${ }^{[15]}$ Vertucci $^{[16]}$ recommended evaluating the base and walls of the pulpal chamber when the number of existing root canals could not be accurately determined.

The typical anatomy of cases with four canals is based on a well-established orifice of an extra mesiolingual canal on a groove. In such cases, the distopalatal canal is also well developed and wide, and it is located more distal compared with teeth with just a single palatal canal. ${ }^{[12]}$ In the present case, as the distopalatal canal orifice was located more distal in comparison with the orifice of the mesiobuccal canal, a secondary palatal canal was suspected. The orifice of the second palatal canal was detected by enlarging the access cavity. In the present case, as the orifice of the secondary canal was wide and well developed, the treatment procedure was the same as that for a maxillary second molar with a single palatal canal. According to a previous study, the prognosis of teeth with two palatal canals was similar to that of a maxillary molar with a single canal. ${ }^{[17]}$

Peikoff et al. ${ }^{[5]}$ classified root canal anatomies of 520 treated maxillary second molars into six groups: three separate roots and three separate canals (class 1); three separate roots and four separate canals (two in the mesiobuccal root) (class 2); three roots and canals, with a separate root at the junction of mesiobuccal and distobuccal canals (class 3); two separate roots, with a single canal in each (class 4); a single main root and canal (class 5 ); and four separate roots and four canals, two of which were palatal canals (class 6). In the present case, the maxillary second molar had five canals: two mesiobuccal, one distobuccal, and two palatal. Considering the morphological root canal system classification by Peikoff et al., ${ }^{[5]}$ the present case seems to be a combination of classes 4 and 6 . Prashanth et al. ${ }^{[18]}$ employed a classification system that was similar to that by Peikoff et al. ${ }^{[5]}$

\section{Conclusion}

All clinicians should be aware of the diversity of canal morphologies and anatomies. In addition, they should consider the possibility of two palatal canals, particularly in cases of second molars and perform radiography for aiding detection of extra canals. When extra canals in teeth cannot be distinguished using conventional radiography, a careful examination of the access cavity and developmental grooves can aid detection of such canals.

Conflict of interest: None declared. 


\section{References}

1. Setzer FC, Boyer KR, Jeppson JR, Karabucak B, Kim S. Long-term prognosis of endodontically treated teeth: a retrospective analysis of preoperative factors in molars. J Endod 2011;37:21-5. [CrossRef]

2. Gutmann JL, Fan B, Tooth Morphology, Isolation and Access. In: Hargreaves KM, Bergman LH, editors. Cohen's Pathways of the Pulp Expert Consult. 11th Edition. Elsevier Inc; 2015. p. 130-208.

3. Sempira HN, Hartwell GR. Frequency of second mesiobuccal canals in maxillary molars as determined by use of an operating microscope: a clinical study. J Endod 2000;26:673-4. [CrossRef]

4. Libfeld H, Rotstein I. Incidence of four-rooted maxillary second molars: literature review and radiographic survey of 1,200 teeth. J Endod 1989;15:129-31. [CrossRef]

5. Peikoff MD, Christie WH, Fogel HM. The maxillary second molar: variations in the number of roots and canals. Int Endod J 1996;29:365-9. [CrossRef]

6. Pécora JD, Woelfel JB, Sousa Neto MD, Issa EP. Morphologic study of the maxillary molars. Part II: Internal anatomy. Braz Dent J 1992;3:53-7.

7. Lee JH, Kim KD, Lee JK, Park W, Jeong JS, Lee Y, Gu Y, et al. Mesiobuccal root canal anatomy of Korean maxillary first and second molars by cone-beam computed tomography. Oral Surg Oral Med Oral Pathol Oral Radiol Endod 2011;111:785-91. [CrossRef]

8. Ulusoy OI, Görgül G. Endodontic treatment of a maxillary second molar with 2 palatal roots: a case report. Oral Surg Oral Med Oral Pathol Oral Radiol Endod 2007;104:e957. [CrossRef]
9. al Shalabi RM, Omer OE, Glennon J, Jennings M, Claffey NM. Root canal anatomy of maxillary first and second permanent molars. Int Endod J 2000;33:405-14. [CrossRef]

10. Green D. Morphology of the pulp cavity of the permanent teeth. Oral Surg Oral Med Oral Pathol 1955;8:743-59.

11. Vertucci FJ. Root canal anatomy of the human permanent teeth. Oral Surg Oral Med Oral Pathol 1984;58:589-99.

12. Christie WH, Peikoff MD, Fogel HM. Maxillary molars with two palatal roots: a retrospective clinical study. J Endod 1991;17:80-4. [CrossRef]

13. Sewerin I. Radiographic examination. In: Bergenholtz G, Hørsted-Bindslev P, Reit C, editors. Textbook of Endodontology* Oxford : Blackwell Publishing Ltd; 2003. p. 215-35.

14. Kottoor J, Hemamalathi S, Sudha R, Velmurugan N. Maxillary second molar with 5 roots and 5 canals evaluated using cone beam computerized tomography: a case report. Oral Surg Oral Med Oral Pathol Oral Radiol Endod 2010;109:e162-5. [CrossRef]

15. Weller RN, Hartwell GR. The impact of improved access and searching techniques on detection of the mesiolingual canal in maxillary molars. J Endod 1989;15:82-3. [CrossRef]

16. Vertucci FJ. Root canal morphology and its relationship to endodontic procedures. End Topics 2005;10:3-29. [CrossRef]

17. Aggarwal V, Singla M, Logani A, Shah N. Endodontic management of a maxillary first molar with two palatal canals with the aid of spiral computed tomography: a case report. J Endod 2009;35:137-9. [CrossRef]

18. Prashanth MB, Jain P, Patni P. Maxillary right second molar with two palatal root canals. J Conserv Dent 2010;13:946. [CrossRef] 